\title{
Tejemos para sanar y desmontar nuestra victimidad: Diálogo con Juana Alicia Ruíz Hernández, coordinadora de la Asociación Mujeres Tejiendo Sueños y Sabores de Mampuján
} Jokabeth Ramos Díaz Granados/ Universidad Del Valle

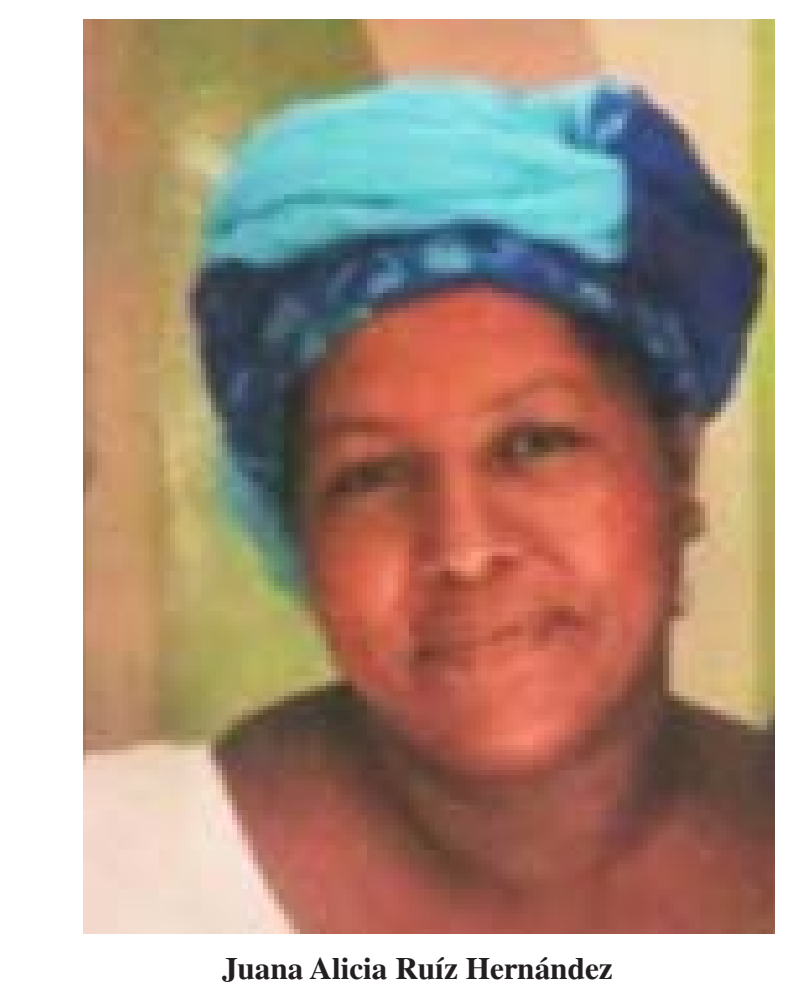

Foto: Jokabeth Ramos Díaz Granados-archivo personal

\section{Introducción}

Mantener viva la memoria como fuente de aprendizaje y enseñanza para las nuevas generaciones, minimizar los impactos dejados por la violencia, aumentar la resiliencia y dejar una memoria histórica para evitar la repetición de los hechos es el sueño que acompaña a Juana Alicia Ruíz Hernández, coordinadora de la Asociación de Mujeres Tejedoras de Sueños y Sabores de Paz de Mampuján, Premio Nacional de Paz 2015.

Este colectivo ha creado una plataforma de enunciación política de demandas regionales, étnicas, de género y de grupos específicos de víctimas en la que recogen la memoria del conflicto armado, recuperan su manera de ser y su dignidad lacerada por la violencia y reivindican el conocimiento de sus derechos para superar la victimidad y la victimización. Comparto el diálogo sostenido con Juana Alicia Ruíz sobre la forma como las mujeres de Mampuján han respondido a la violencia y el desplazamiento con resilencia y solidaridad a través del tejido.

\section{JRDG: ¿Quién es Juana Alicia Ruiz Hernández?}

$J A R H$ : Étnicamente me considero negra afrodescendiente. Nací hace 43 años en una finca del corregimiento de San Pablo (Bolívar), fui la hija once de Carmen Alicia Hernández y Miguel Ruiz. Estudié nutrición y salud en una universidad de la ciudad de Barranquilla y luego me especialicé en investigación aplicada a la educación. Soy docente y actualmente líder de la asociación de Mujeres Tejedoras de Sueños y Sabores de Paz de Mampuján. 


\section{JRDG: ¿Cuáles han sido las experiencias de vida frente al desplazamiento?}

JARH: El día del desplazamiento me encontraba estudiando en Barranquilla y me enteré porque familiares y amigos comenzaron a informarme de lo que estaba pasando. Entonces, empecé a preocuparme porque había un abandono completo por las víctimas. Por ese tiempo, María La Baja tenía un alcalde encargado que se sentía impedido para tomar decisiones porque el anterior alcalde estaba siendo investigado. Esta falta de gobernabilidad desafortunadamente llevó a las víctimas a tener que permanecer por algún tiempo en el parque principal del pueblo hacinados en carpas provisionales que algunos de la comunidad iban donándoles. Con los meses, la alcaldía autorizó la reubicación de la población en colegios y en antiguas casas que habían servido como prostíbulos. Fue un trato indigno. Sin embargo, la comunidad seguía estando unida como un colectivo yo pienso que esto tiene que ver con nuestros ancestros africanos.

\section{JRDG: ¿Cómo lograron el asentamiento en el Nuevo Mampuján?}

JARH: A medida que iba pasando el tiempo también iban aumentado los problemas. Llegó el momento en que se acabaron las vacaciones escolares. Los estudiantes debían regresar a las clases y necesitaban que las víctimas abandonaran los establecimientos escolares; paralelamente a esto, también con las casas que la alcaldía había alquilado (después de tanto insistirles en que lo hicieran y que se convirtieron en albergues). Los dueños de esos establecimientos comenzaron a sacar las personas y echarlos a la calle porque les debían varios meses de arriendo. Entonces fue cuando el sacerdote Salvador Mura, al ver esta situación, buscó recursos en Italia para que la comunidad comprara un terreno en el cual establecerse. Al principio fueron pocas las familias que se pasaron a vivir en él pero poco a poco el terreno se fue llenando de construcciones hasta convertirse en lo que es hoy el Nuevo Mampuján.

\section{JRDG: ¿Y cómo se dio el proceso de reparación a las víctimas?}

JARH: Luego del asentamiento, comenzó el proceso jurídico que resultó más complejo de lo que esperaba la comunidad porque muchos no tenían ni la menor idea de cómo hacer los trámites y no estaban acostumbrados a este tipo de procedimientos. Sin embargo, fuimos aprendiendo asistiendo a las reuniones y debates; tuvieron que pasar once años desde que ocurrió el desplazamiento para que se diera la primera sentencia de Justicia y Paz y se expidiera el comunicado del fondo para la reparación a las víctimas de nuestra comunidad y las comunidades vecinas que habían sido afectadas por las atrocidades cometidas por miembros del paramilitarismo. Ese mismo día que llegaron las delegadas del gobierno a darnos a conocer el fallo de la sentencia, nos reunimos en nuestra iglesia y allí creamos un comité de seguimiento.

\section{JRDG: ¿Cuál fue el rol que desempeñaron las mujeres durante todo ese tiempo?}

JARH: Durante el tiempo que duró el desplazamiento las mujeres no tuvimos ni voz ni voto y aunque en algunas ocasiones nos permitían participar en las reuniones que los hombres hacían con los organismos del estado. Nuestras opiniones nunca eran tenidas en cuenta. Ellos decían que esa función solo les correspondía por ser los jefes de los hogares y que nuestra función era obedecerles y cuidar de los hijos. A mí, en particular, me preocupaba esa situación, al igual que otras mujeres. Comenzamos a preguntarnos si, en realidad, la función de nosotras debería ser seguir haciendo las labores del hogar y dejar que solo ellos tuvieran la responsabilidad de tomar las decisiones sobre los proyectos de la comunidad. La mayor parte del tiempo las mujeres nos la pasábamos pensando qué hacer para ayudar a la comunidad. Teníamos tantas ideas, pero los hombres no nos dejaban actuar. Nos sentíamos con las manos atadas, impotentes, sin saber qué hacer. Yo veía cómo muchas de las mujeres lloraban recordando la vida en Mampuján y sufrían en silencio, y esto me inquietaba mucho.

\section{JRDG:¿Cómo nace la asociación Mujeres Tejedoras de Sueños y Sabores de Paz de Mampuján?}

JARH: Sentía que las mujeres de la comunidad cargaban una tristeza y un dolor por todo lo que estaba pasando y eso se reflejaba en sus rostros. Fue entonces cuando nos reunimos un grupo de mujeres y decidimos organizarnos para buscar una ayuda profesional. Se trataba primero de sanar las heridas que habían causado en ellas el desplazamiento; por eso acudimos a la fundación Sembrando Paz de Sincelejo. En ella a Ricardo Esquivia, presidente de la fundación y dirigente del Comité Central Menonita, se le ocurrió la idea de invitar a Teresa Geiser psicóloga y artista para que desde la experiencia que había tenido con otras comunidades en Centroamérica, en circunstancia similares a la nuestra, pudiera ayudarnos a sanar el duelo. En esos talleres de sanación, Teresa utilizó una técnica conocida como "Quilt". El procedimiento con esta técnica consistía en coser tela sobre tela al principio: era unir la tela hasta formar lo que llamamos por acá las colchas de cuadritos. Pero nosotras tuvimos la idea y se la compartimos a Teresa que porqué no comenzábamos a trabajar tejiendo sobre la tela figuras con las cuales pudiéramos plasmar nuestros recuerdos que teníamos de Mampuján y así ir rescatando nuestra tradición oral, nuestra memoria y al mismo tiempo sanar nuestros traumas. Teresa estuvo de acuerdo y así fue como comenzamos a tejer nuestros tapices. 
JRDG: ¿Y cuáles han sido las experiencias que han vivido las mujeres de la asociación con los tapices?

JARH: Cuando comenzamos a tejer los tapices sentíamos mucha tristeza y dolor, recordábamos todo el pasado y veíamos cómo, entre puntada y puntada, las lágrimas iban cayendo $\mathrm{y}$, en ocasiones, teníamos que parar porque no dejábamos de llorar. Con el pasar del tiempo, el tejido se convirtió en un instrumento de catarsis pues, a través de él, comenzamos a exteriorizar nuestros sentimientos de tristeza, sanar nuestros traumas e ir recuperando la memoria colectiva y hasta volvimos a sonreír, porque habíamos perdido hasta esa capacidad. Hoy día vemos otra realidad, las mujeres que pertenecemos a la Asociación de Mujeres Tejiendo Sueños y Sabores de Paz de Mampuján. Somos muy diferentes a como éramos antes. Muchas nos hemos convertido en lideresas comprometidas no solo con el bienestar de la comunidad de Mampuján sino también con otras comunidades que, al igual que la nuestra, han tenido que vivir los horrores del conflicto armado. Nuestro compromiso es tan grande, que hemos estado en varias regiones de Colombia haciendo talleres de sanación de duelo y enseñándole a muchas mujeres a trabajar la memoria oral como una práctica de reconciliarnos, primero con nosotras mismas y luego con los demás. En esta práctica colectiva, hemos aprendido que el perdón es sanación y que esa sanación nos convierte en mejores personas. Nuestra labor no termina hoy porque hay mucho por hacer todavía. Hay víctimas del conflicto que necesitan que se les ayude así como a nosotras nos ayudaron un día. Estamos dispuestas a ir donde nos necesiten; lo hacemos sin ánimo de lucro. Lo que nos hemos propuesto es tejer una red de solidaridad con las mujeres víctimas del conflicto armado en Colombia y si se puede más adelante con otras mujeres del sur y centro de América.

\section{JRDG:¿Qué le significó a ustedes haber recibido el Premio Nacional de Paz 2015?}

$J A R H$ : Una alegría muy grande, no lo podíamos creer, no nos imaginábamos que nuestra labor había llegado tan lejos y ser merecedoras de ese galardón. Al principio nos dio susto pensar en el viaje a Bogotá para recibir el premio. Nos preguntábamos cómo íbamos hacer y que íbamos a decir cuando estuviéramos allá, pero poco a poco, fuimos preparándonos y de la mano de Dios las cosas se fueron dando. Eso sí, no pudimos evitar llorar por la emoción que sentíamos, estábamos felices porque para nosotros, ese premio significa el reconocimiento a nuestra labor y compromiso con la paz pero también, el reconocimiento y valor que las mujeres merecemos porque en este país, los hombres tienen una deuda muy grande con nosotras las mujeres.

\section{JRDG: ¿Y qué viene ahora con el premio?}

JARH: Tenemos muchos proyectos que ya comenzamos hacerlos realidad gracias al dinero que recibimos con este reconocimiento. El primero de ellos ha sido la compra del terreno donde se construirá la sede de nuestra Asociación, que constará de varias aulas para reuniones, talleres de capacitación en artes y otros espacios que estarán dotados para la producción de conservas y dulces típicos, que hacen honor al nombre de la Asociación y que hemos venido elaborando con las recetas de las abuelas. En este proyecto, hemos contado con el apoyo de varias organizaciones y empresarios colombianos. De esta forma, hemos venido abriendo un espacio en el comercio, especialmente en ciudades como Bogotá y en algunos aeropuertos del país. 